\title{
Proceeding
}

Asia Pacific Conference on Performance Analysis of Sport, 21-24 April 2014. Langkawi, Malaysia.

\section{The kicking performance by different boots material}

\author{
ZULKIFLI AHMADA , MOHD AMINUDDIN PI REMLIB, MOHD HAZIQ NORDINC, \\ NASRUL HADI JOHARID \\ Human Engineering Group, Faculty of Mechanical Engineering, Universiti Malaysia Pahang, 26600, Pekan, Pahang, \\ Malaysia
}

\begin{abstract}
Ahmada, Z., Aminuddin, M., Nordinc, M.H., \& Joharid, N.H. (2015). The Kicking Performance by Different Boots Material. J. Hum. Sport Exerc., 9(Proc2), pp.S657-S665. Introduction: The purpose of this study was to investigate the kinematics of kicking by experimental and simulation techniques analysis. The differences of material stiffness will affected to the ball velocities. Experimental setup by high speed video camera with 250 frames per second was performed in order to obtain the foot and ball velocities during the kicking process. There are 10 male football players from majlis sukan negeri terengganu (MSNT) were selected as subjects. Instep kicking with right foot was choosing due to the highest ball velocities can be produced by this technique. Simulation analysis by finite element analysis (FEA) then used to validate the results from experimental work done. Polyethylene material and $2.0 \mathrm{~mm}$ thickness from boot $\mathrm{c}$ was considered as the best boot design compared to the others. It gives the highest maximum stress and the highest force to produce the highest ball velocity. The other variables related to the ball velocity such as coefficient of restitution (COR) and contact time. This study is useful to design the suitable material for each region of boots. It also can help the athletes to identify the characteristics of boot selection for different position on the field. Key words: MATERIAL, KICKING, BALL VELOCITY.
\end{abstract}

Corresponding author. Universiti Malaysia Pahang, 26600, Pekan, Pahang, Malaysia

E-mail: kifli@ump.edu.my

Asia Pacific Conference on Performance Analysis of Sport, 21-24 April 2014. Langkawi, Malaysia.

JOURNAL OF HUMAN SPORT \& EXERCISE ISSN 1988-5202

(C) Faculty of Education. University of Alicante

doi:10.14198/jhse.2015.10.Proc2.03 


\section{INTRODUCTION}

Football is the most popular team sports game with over a billion television audiences around the world (Kellis \& Katis, 2007; Price, Jones \& Harland, 2006). The games give full enjoyment to those who are watching or playing it. This is due to the skills applied in this sport such as control play, counter attack, running, dribbling, passing and kicking which are commonly used during the game. However, the fastest kicking is not only the power produced by the foot but the boot material also plays an important factor in kicking. Generally, football boot is functioned to serve as an interface between the foot and the ball in order to provide the player comfort. Furthermore, it can protect the player foot from injury due to the repeated and prolonged usages (Carmont, Chaudhry \& McBride, 2004).

Good kicking technique is the most typical specific technique of kinesiology in the football game. In order to understand the scientific work behind this skill, fundamental of kicking kinematics movement is particularly important for guiding and monitoring the training process (Kellis \& Katis, 2007; Lees, Asai, Andersen, Nunome \& Sterzing, 2010). This movement is the motion like a transferred an energy from proximal to the distal acceleration motion pattern (Kellis \& Katis, 2007). That energy is moved from trunk to the pelvis, thigh, and leg and then transform to the energy in ball deformation. Based on all types of kicking, direct shot or instep kick was the highest velocity can be performed (Andrew \& Neal, 2012; Hong, Chung, Sakamoto \& Asai, 2011). In addition, the full instep kicking give the highest result in kicking accuracy compared to inner instep and side foot kick (Sterzing, Lange, Wächtler, Müller \& Milani, 2009). The more deformation created, the more energy has transferred and increasing the ball speed. The ball speed and trajectory are not only correlated with the how much force will be produced by the player foot but more than that such as material (Sterzing, Müller, Wächtler, \& Milani, 2011), shoe mass (Andrew \& Neal, 2012), foot anthropometry (Zulkifli \& Aris, 2013), design, gender (Sakamoto, Geisler, Nakayama \& Asai, 2010), type of kicking (Hong, Kazama, Nakayama, \& Asai, 2012; Sterzing et al., 2009), and skills. In this study, we emphasize the material properties and design of the boot itself.

To date, improvement of advanced material's technology is increased abruptly. The technology can produce new synthetic material, which is the lightest, thinnest, and strongest. This phenomenon influenced the football boot's industry as well. The sports leading companies such as Nike, Adidas, and Puma provides competitiveness among them with design and image brands. The different material properties provide the different characteristics that effect to the ball dynamics such as friction (Sterzing \& Hennig, 2007), impact, coefficient of restitution (Ismail, Mansor, Ali, Jaafar \& Johar, 2010) and contact time. However, some of the companies still produce the football boot made by animal skin such as kangaroo leather (K-leather) and calf skin in terms of comfort criteria and demand by customer. Furthermore, that material has light-weight property to get a comfort condition when wearing it. Based on the research done by Andrew and Neal (2012), the weight of the boot will not affect the velocity of the ball after impact of kicking. Thus, if the synthetic material will replace the function of K-leather, indirectly it can reduce the number of poachers killing the animals.

Wearing the wrong boot can caused injuries and brings harm to the player foot. However, some people conclude that, the comfort and fit boot are the best chosen to wear rather than other criteria. This statement is totally wrong because the best chosen boot is different for each person. It is depend on many factors such as foot anthropometry, bone structure, and foot shape. Metatarsal bone on the upper forefoot is the common area of injuries occurred. Asai, Carré, Akatsuka, \& Haake (2002) reported that region produced the high stress and close impact when simulated the interaction between instep kick and the ball. On the other hand, ankle joint will affect to the foot when performed the instep kick. It proves by Fraser, Harland, 
Donovan, and O'Shea (2012), which plantar flexion deformation can caused the ankle joint moment using end-effector simulator. This mechanical simulator is to provide repeatable contact between foot and the ball with changes the rubber stiffness on the instep location.

The goal of this study is to investigate the kinematics of kicking by experimental and simulation. Hence, this study observed the relationship between the various kinematic variables such as maximum velocity, contact time, and coefficient of restitution of the ball. Then, simulation analysis was performed for validation the results obtain in experimental work. The different materials and thickness of boot were expected to produce the different ball velocities. Furthermore, the hypothesis of this study is the different stiffness of materials produced the different impact of ball speed.

\section{METHODOLOGY}

\section{Experimental Setup}

Ten male football players from Majis Sukan Negeri Terengganu (MSNT) were selected as subjects. The average and standard deviation of age, height, and weight were 15.8( \pm 0.63$)$ years old, $169.49( \pm 26.64) \mathrm{cm}$ and $57.16( \pm 4.83) \mathrm{kg}$ respectively. In order to retain homogeneity, only right foot of the football player was chosen for this experiment. A high speed video camera was used to capture the impact between the boot and the ball, in terms of ball deformation and coefficient of restitution (COR). To investigate the different material of boots, three different type of boot brand were used by player. These three boots have their own capabilities and advantages each other. The most widely studied about football kick in biomechanical research is the instep kick (Apriantono, Nunome, Ikegami \& Sano, 2006). Therefore, instep kick was chosen as the common technique in kicking due to it can produce the highest velocity compare to the others kicking techniques (Levanon \& Dapena, 1998). The human variable uncertainties such as strength of kicking, location of impact, type of kicking, speed and angle of foot are very hard to control for each repetition. Hence, this experiment was attempted to be constant as possible with three times of attempting.

A standard soccer ball size 5 with weighing $0.430 \mathrm{~kg}$ and diameter $220 \mathrm{~mm}$ was employed. There is two high definition of the spotlight were focused on the ball to ensure the impact can be captured well by high speed camera (250 frames per second). Experimental setup for this study was illustrated in Figure 1 with capture image in the box. The subject shot the ball on the force plate towards a goal. The high speed camera was captured the boot and ball before, during and after the impact of kicking. Three times of attempts were repeated to obtain the average data. Then, the subject takes a rest before continued for the next kicking with change the shoes to prevent the muscle fatigue which influences the performance. There are markers were place on the boot to measure the angle of foot, and foot velocity during performed the instep kick. The high speed video camera was used to capture the image frame by frame for all movements done. 


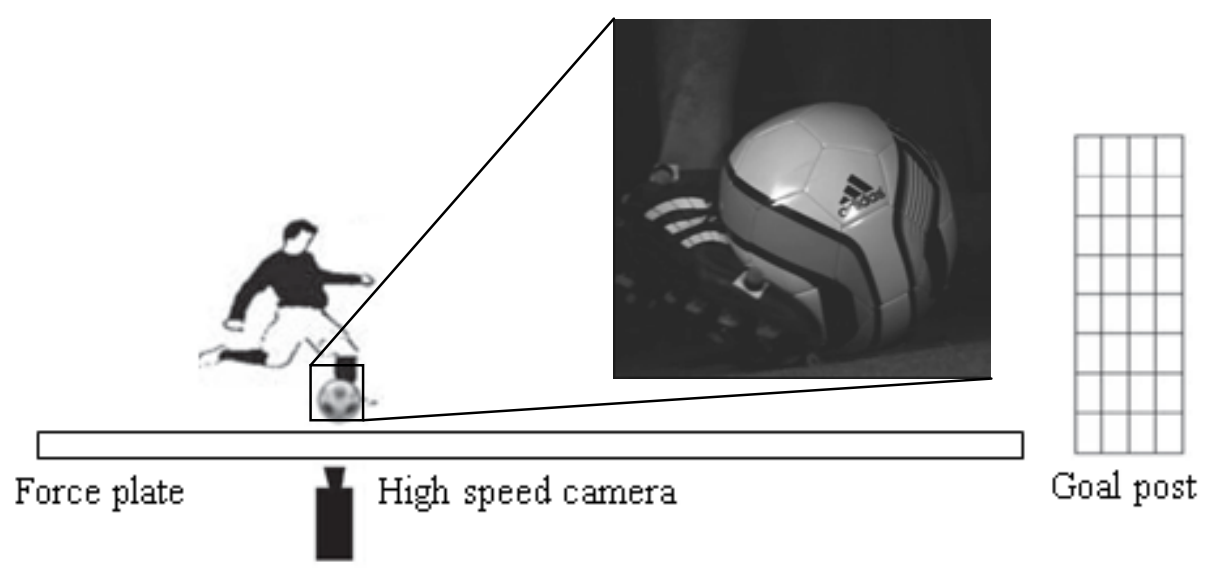

Figure 1. Experimental Setup

Impact is one of considered variables either in the experiment or simulation. It can be seen through frames taken by the high speed camera. The highest deformation will produce the highest impulse to release the energy. Impulse is the product of force multiplied by the time that forces acts. As a result, the important related equation to presents this problem is impulse-momentum equation in Eq. 1.

$$
\sum F \Delta t=m\left(v_{2}-v_{1}\right)
$$

Eq. 1

The mechanism of collision between the foot and the ball could be described by the following equation (Lees \& Nolan, 1998) (Eq. 2);

$$
V_{\text {ball }}=V_{\text {foot }} \frac{M \cdot(1+l)}{(M+m)}
$$

Eq.2

Where $V_{\text {ball }}=$ velocity of the ball, $V_{\text {foot }}=$ velocity of the foot, $M=$ effective striking mass of the leg, $m=$ mass of the ball and $\ell=$ the coefficient of restitution. The term $(1+\ell)$ is related to the firmness of the foot at impact and the ratio $\mathrm{M} /(\mathrm{M}+\mathrm{m})$ provides an indication of the rigidity of the foot and leg at impact.

Instep kick is the highest velocity compare to side foot kick (Levanon \& Dapena, 1998; Nunome, Asai, Ikegami \& Sakurai, 2002). From a research of instep kick by (Ismail et al., 2010) the result show that the maximum instep kick velocity was range between $18 \mathrm{~m} / \mathrm{s}$ to $35 \mathrm{~m} / \mathrm{s}$. Instep kicking technique had been researched from intermediate to the professional player (Asami \& Nolte, 1983). In an instep kicking, the highest velocity of kick will be the upper hitting that is with the velocity of $37.31 \mathrm{~m} / \mathrm{s}$ followed by middle hitting and lower hitting that are $28.89 \mathrm{~m} / \mathrm{s}$ and $24.78 \mathrm{~m} / \mathrm{s}$ respectively (Asai, Akatsuka \& Kamata, 1996).

Simulation analysis

The simulation started with creating the 3D model of ball and football boot (Figure 2) using CAD software. Model of football boot is based on the real dimension, wearing by the player to kicking the ball. Since, the real shape of boots are very complicated and irregular surface, thus simplified model was presented here in order to make the simulation easier. However, this model should be ensuring under acceptable condition. 
Due to the focusing on the uppersole material, a layer of material was create on that area to observe the changes in ball deformation by changes the material stiffness (Figure 2). Then, the impact of the kicking can be used to measure the force exerted by calculation. The simulation method was performed to validate the results that had been obtained previously by experimental.

The 3D models are saved in step format file before imported by Finite Element Analysis (FEA) software. The orientation of the ball and boot was arranged as position of instep kicking with the distance is close each other. It will help us to compare the result in real condition and decrease time consumption for analysis.
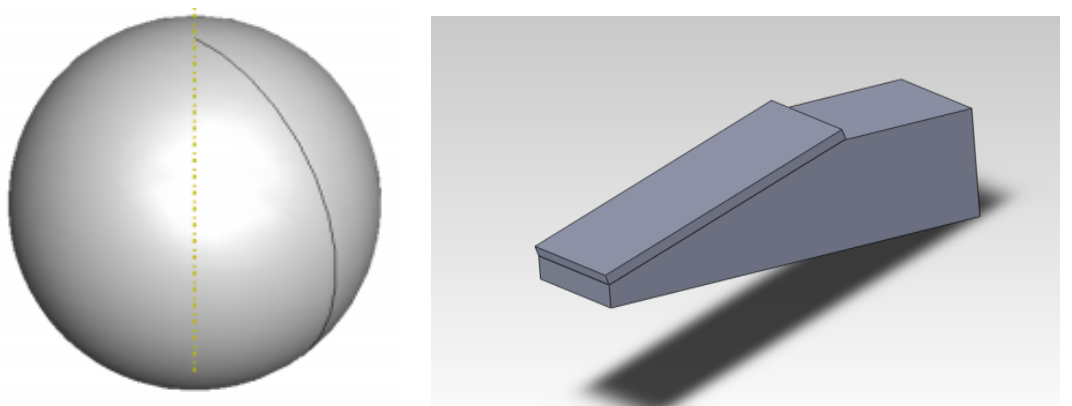

Figure 2. (a) Ball and (b) Football boot models

Explicit dynamic analysis is suit to perform the instep kicking in this simulation, this is due to the motion of foot and ball after impact can be determined. Elastic and hyperelastic materials were assigning for football boot and ball respectively. The ball model was created by making it hollow in the middle and pressure inside is 0.65 bar. This is follow the FIFA standard and real ball used in the experiment. The material properties and thickness of uppersole was varying for each different boots. These variables were sorting in the Table 1.

Table 1. Material and thickness of three different boots

\begin{tabular}{clc}
\hline Brand & Materials & Thickness $(\mathrm{mm})$ \\
\hline A & Polyamides & 2.8 \\
B & Polyethylene & 1.2 \\
C & Polyester & 2.0 \\
\hline
\end{tabular}

\section{RESULTS AND DISCUSSION}

Experimental result such as foot velocity, ball velocity, and contact time can be analysing from high speed video camera. The movement of foot divided by each frame per second can be used to measure the foot and ball velocity. The measurement of velocity was captured by high speed camera started from just before the foot touches the ball until it released the ball. Referring to the Eq. 1, impulse-momentum relationship represents the speed of the ball was depended on the force of impact and time contact between boot and ball. Figure 3 indicates that the ball deformation of three different boots. 

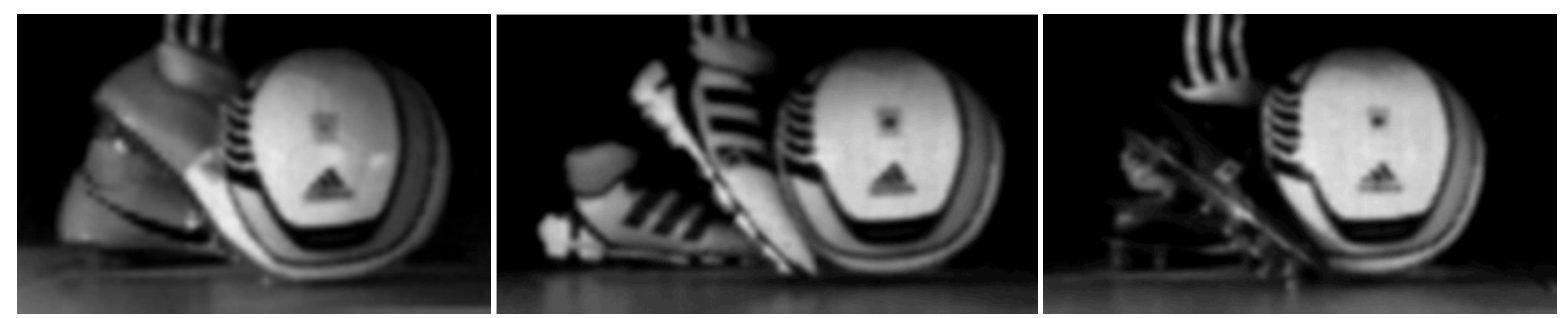

Figure 3. Ball deformation during impact for boot $A, B$ and $C$

Table 2. Experiment results

\begin{tabular}{ccccccc}
\hline Brand & $\begin{array}{c}\text { footbefore, } \\
(\mathrm{m} / \mathrm{s})\end{array}$ & $\begin{array}{c}\text { footater, } \\
(\mathrm{m} / \mathrm{s})\end{array}$ & $\begin{array}{c}\text { ball } \mathrm{lfter}_{\text {ar, }} \\
(\mathrm{m} / \mathrm{s})\end{array}$ & $\begin{array}{c}\text { Contactime, } \\
(\mathrm{s})\end{array}$ & COR & Force $(\mathrm{kN})$ \\
\hline$A$ & 28.85 & 18.01 & 36.81 & 0.0176 & 0.6 & 5.830 \\
$B$ & 29.00 & 19.41 & 37.05 & 0.016 & 0.6 & 5.633 \\
$C$ & 28.11 & 18.71 & 37.98 & 0.015 & 0.6 & 5.778 \\
\hline
\end{tabular}

The longest contact time was performed by boot $B$ followed by boot $A$ and $C$ with increasing ball velocity produced. In easier conclusion is the longest contact time between ball and boot will reduce the ball velocity. It is due to the material was absorbed the impact and reduce the ball velocity as well. Kellis \& Katis (2007) also reported that to get the highest ball velocity the shorter the foot-ball contact situation must be performed. It stated that the brand $\mathrm{C}$ produced the highest ball velocity compared to the others brand. It is due to the momentum of impact from the leg being transferred to the ball and produced the kinetic energy of this motion. On the other hand, this impact can relate to the material stiffness of football boot. It comply the rule of stiffness and impact relationship, which is the high impact produced by the highest material stiffness contact. In addition, it can be prove by the leg velocity before the impact is the lowest but can achieved the highest ball velocity.

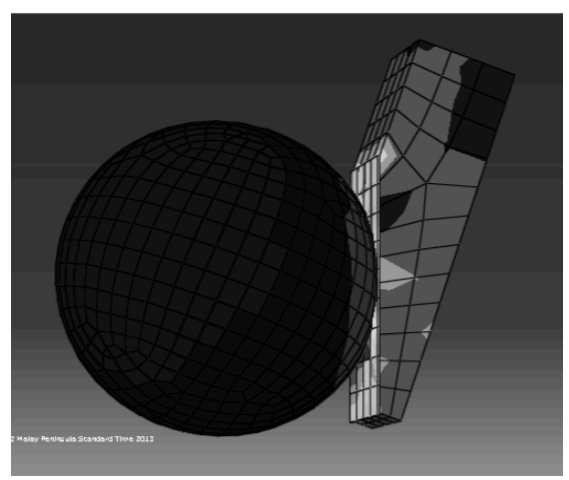

Figure 4. Simulation of football boot and the ball

By simulation techniques, Figure 4 illustrates that the stress is huge exerted at the uppersole of the football boot. This is due to the instep kicking technique used that region to give impact to the ball as well as transfer the energy to create ball deformation. The higher ball deformation, for sure the high velocity can be 
performed. From observation, the critical impact and high stress was located at the metatarsal region of the upper foot area. It can proved the research done by Asai et al. (2002), which is instep kicking will affected to the metatarsal region. When changing boots, it is actually change the material and thickness as well. These variables change the stiffness of the materials on the uppersole area. However, the best boot brand is the best material to prevent the injury by reducing the impact to the foot. The summary of the high stress distribution was presented in Table 3.

Table 3. Stress analysis for different materials

\begin{tabular}{ccc}
\hline Materials & Stress $(\mathrm{MPa})$ & Force $(\mathrm{N})$ \\
\hline Polyamides & $3.40 \times 10^{-2}$ & $4.53 \times 10^{3}$ \\
Polyethylene & $1.41 \times 10^{-2}$ & $2.90 \times 10^{3}$ \\
Polyester & $3.57 \times 10^{-2}$ & $5.80 \times 10^{3}$ \\
\hline
\end{tabular}

Referring to the Table 3, Polyester produced the highest stress value that is $0.036 \mathrm{MPa}$ follow by Polyamides $0.034 \mathrm{MPa}$ and Polyethylene $0.014 \mathrm{MPa}$. Furthermore, for the force impact, the sort of materials also for Polyester, Polyamides and Polyethylene with force $5.80 \mathrm{kN}, 4.53 \mathrm{kN}$, and $2.90 \mathrm{kN}$ respectively. The difference between all the stresses for each material is due to the structure characteristics of that material. The highest stress indicates that the high force of impact can be absorbed by the football boot, and it can transfer the high energy from the foot to the ball directly. Therefore, brand $\mathrm{C}$ can be performed well during the kicking. In terms of material selection, this analysis showed that polyester is considered as the best material for kicking applications to produce the highest ball velocity. However, for the other side, this material is the highest possibility cause injury because it creates the highest force to the foot. However, that value which is $5.80 \mathrm{kN}$ is still consider small compared to the others.

Last analysis is to identify the optimum thickness for each football boot. The results found that there is no huge effect for these variables since the stress given too small value. Also, the brand $\mathrm{C}$ give the highest stress with $0.83 \mathrm{~Pa}$ even though with the second thicker among the boot selection. This value is considered as no relationship with the ball velocity.

\section{CONCLUSION}

In conclusion, the objective of this study to determine the correlation between material properties and ball speed during kicking was achieved. The different types of materials have different type of stiffness and represents by the results of ball speed. The material stiffness and ball speed are closed correlation. Polyester becomes the highest stress and impacted of the ball compared to the polyamides and polyethylene. Moreover, there is no huge effect of the thickness parameters to the force and stress due to the small thickness ranging of boots uppersole between $2.8 \mathrm{~mm}$ for boot $A, 1.2 \mathrm{~mm}$ for boot $B$ and $2.0 \mathrm{~mm}$ for boot $C$. For overall conclusion, boot $C$ is considered as the best combination of boot's material and thickness in terms of ball velocity. The suggestion for the future to improve this study is to compare those boots based on the different type of shooting, passing, and tackling. Thus, the material and design advantage for each boot can be determined and evaluated properly. 


\section{REFERENCES}

1. Andrew, M., \& Neal, S. (2012). Effect of shoe mass on soccer kicking velocity. Paper presented at the 30th Annual Conference of Biomechanics in Sports, Melbourne.

2. Apriantono, T., Nunome, H., Ikegami, Y., \& Sano, S. (2006). The effect of muscle fatigue on instep kicking kinetics and kinematics in association football. Journal of sports sciences, 24(1), pp.951960.

3. Asai, T., Akatsuka, T., \& Kamata, Y. (1996). Impact simulation of kicking using fluid and structure interaction analysis. Paper presented at the ISBS-Conference Proceedings Archive, 14 International Symposium on Biomechanics in Sports.

4. Asai, T., Carré, M., Akatsuka, T., \& Haake, S. (2002). The curve kick of a football I: impact with the foot. Sports Engineering, 5(4), pp.183-192.

5. Asami, T., \& Nolte, V. (1983). Analysis of powerful ball kicking. Biomechanics VIII-B. 4, pp.965970.

6. Carmont, M.R., Chaudhry, S., \& McBride, D.J. (2004). Clutch foot stress fracture: another complication of commuting? Foot and Ankle Surgery, 10(3), pp.159-162. doi: 10.1016/j.fas.2004.04.002

7. Fraser, S., Harland, A., Donovan, P., \& O'Shea, L. (2012). Development of an end-effector to simulate the foot to ball interaction of an instep kick in soccer. Procedia Engineering, 34, pp.284289.

8. Hong, S., Chung, C., Sakamoto, K., \& Asai, T. (2011). Analysis of the swing motion on knuckling shot in soccer. Procedia Engineering, 13(1), pp.176-181. doi: 10.1016/j.proeng.2011.05.069

9. Hong, S., Kazama, Y., Nakayama, M., \& Asai, T. (2012). Ball impact dynamics of knuckling shot in soccer. Procedia Engineering, 34, pp.200-205.

10. Ismail, A., Mansor, M., Ali, M., Jaafar, S., \& Johar, M. (2010). Biomechanics Analysis for Right Leg Instep Kick. Journal of Applied Sciences, 10(13), pp.1286-1292

11. Kellis, E., \& Katis, A. (2007). Biomechanical characteristics and determinants of instep soccer kick. Journal of sports science \& medicine, 6(2), pp.154.

12. Lees, A., Asai, T., Andersen, T. B., Nunome, H., \& Sterzing, T. (2010). The biomechanics of kicking in soccer: A review. Journal of sports sciences, 28(8), pp.805-817.

13. Lees, A., \& Nolan, L. (1998). The biomechanics of soccer: a review. Journal of sports sciences, 16(3), pp.211-234.

14. Levanon, J., \& Dapena, J. (1998). Comparison of the kinematics of the full-instep and pass kicks in soccer. Medicine \& Science in Sports \& Exercise, 30(6), pp.917-927.

15. Nunome, H., Asai, T., Ikegami, Y., \& Sakurai, S. (2002). Three-dimensional kinetic analysis of sidefoot and instep soccer kicks. Medicine and Science in Sports and Exercise, 34(12), pp.2028-2036.

16. Price, D. S., Jones, R., \& Harland, A. R. (2006). Soccer ball anisotropy modelling. Materials Science and Engineering: A, 420(1-2), pp.100-108.

17. Sakamoto, K., Geisler, G., Nakayama, M., \& Asai, T. (2010). Kinematics of the foot joint in female soccer players during the ball impact phase of kicking. Procedia Engineering, 2(2), pp.2549-2554.

18. Sterzing, T., \& Hennig, E. M. (2007). The Influence Of Friction Properties Of Shoe Upper Materials On Kicking Velocity In Soccer. Journal of Biomechanics, 2(0), pp.195.

19. Sterzing, T., Lange, J., Wächtler, T., Müller, C., \& Milani, T. (2009). Velocity and accuracy as performance criteria for three different soccer kicking techniques. Paper presented at the ISBSConference Proceedings Archive, 27 International Conference on Biomechanics in Sports.

20. Sterzing, T., Müller, C., Wächtler, T., \& Milani, T. L. (2011). Shoe influence on actual and perceived ball handling performance in soccer. Footwear Science, 3(2), pp.97-105. 
21. Zulkifli, A., \& Aris, M. A. (2013). Relationship of Young Athlete Foot Anthropometry Measurement and Kicking Ball Velocity. Paper presented at the International Conference on Computing, Mathematics and Statistics, Bayview Beach Resort Penang, Malaysia. 